\title{
GRAIN SIZE PREDICTION OF ALLOY 718 BILLET FORGED BY RADIAL FORGING MACHINE USING NUMERICAL AND PHYSICAL SIMULATION
}

\author{
Motoi Yamaguchi , Satoshi Kubota ${ }^{*}$, Takehiro Ohno ${ }^{* * *}$, \\ Toshiaki Nonomura ${ }^{* *}$, Tsuyoshi Fukui ${ }^{* *}$ \\ "Metallurgical Research Laboratory, Hitachi Metals, Ltd. \\ Y**asugi Works, Hitachi Metals, Ltd. \\ ${ }^{* * *}$ Chubu Branch, Hitachi Metals, Ltd.
}

\begin{abstract}
Fine grains are required for Alloy 718 to obtain its high strength. Since grain size is strongly affected by forging conditions, many trial forgings are generally needed. On the other hand, grain size predictions by several simulations have been tried to reduce trial forgings. The purpose of this study is to predict grain size of Alloy 718 by combining a numerical simulation and a physical simulation. Firstly the transitions of temperature and strain of the forged material during hot forging were calculated by the 3-dimensional FEM. Secondly multi-stage plane strain compression tests using small test pieces were carried out by means of the Gleeble system according to the temperature and strain programs obtained by the numerical simulation, then the grain size was observed. These simulations were applied for predicting and refining the grain size of Alloy 718 billet forged by hydraulic 4-ram radial forging machine.
\end{abstract}

\footnotetext{
Superalloys 718.625, 706 and Various Derivatives

Edited by E.A. Loria

TMS (The Minerals, Metals \& Materials Society), 2001
} 


\section{Introduction}

Fine grains are required for Alloy 718 disks mainly used for gas turbines to obtain its high strength. To obtain the fine grain disks, it is necessary to refine the grains of the billets of which the disks are made by means of die forging. But it is difficult to refine the grains of large section size billets, especially at center position $(1,2)$.

Alloy 718 billets have been generally forged by 2 -ram press or 4-ram mechanical radial forging machine (GFM) (1-8). In this study, 4-ram hydraulic radial forging machine, called SMX (by SMS EUMUCO Inc.), was used to forge Alloy 718 billets. SMX has advantages over the 2-ram press; its forging speed is higher and straighter and more truly round billet can be obtained. SMX also has advantages over GFM. The maximum load can be added throughout the full stroke by SMX whereas it can be added near the only bottom dead point by GFM. So the reduction in pass of SMX can be controlled, although that of GFM must be set a small value. Therefore SMX can easily control the forging conditions. These advantages are effective to obtain fine grains of all the regions of large section size billets.

On the other hand, since grain size is strongly affected by the forging conditions, many trial forgings, which are very expensive especially for the high price materials such as Ni base superalloys and take much time, are generally needed to control the microstructure. Therefore grain size predictions by several simulations have been tried to reduce trial forgings $(1,2,4-8)$. FEM (Finite Element Method) has been used to predict the strain and the temperature distribution and the microstructure including the grain size of forged products. Not only 2-dimensional FEM but also 3-dimensional FEM must be used for the forging by 2-ram press and 4-ram press, because the deformation behavior of these forgings is complicated. But grain size predictions only by FEM or other equations are difficult for highly-alloyed metals, because the grain growth and recrystallization behavior is very complicated. Especially, the grain sizes of Alloy 718 are strongly affected by the precipitation of delta phase.

The purpose of this study is to predict grain size of Alloy 718 by combining a numerical simulation and a physical simulation, then to establish the fine grain in all the regions of large section size billet (Not only near the surface but also at center position). Firstly the transitions of temperature and strain of the forged metal during hot forging were calculated by the 3-dimensional FEM software DEFORM-3D (by Scientific Forming Technologies Co.). Secondly multi-stage plane strain compression tests using small test pieces were carried out by means of the Gleeble system (by Dynamic Systems Inc.) according to the transitions of the temperature and the strain calculated by the numerical simulation, then the microstructures of small test pieces were investigated. These simulations were applied for predicting and refining the grain size of Alloy 718 billets with $155 \mathrm{~mm}$ and $220 \mathrm{~mm}$ in diameter forged by hydraulic 4-ram radial forging machine.

\section{Numerical Simulation}

\section{Procedures of Simulations}

In this hydraulic radial forging, billets are compressed from 4 directions, then fed and rotated as shown in Figure 1. 


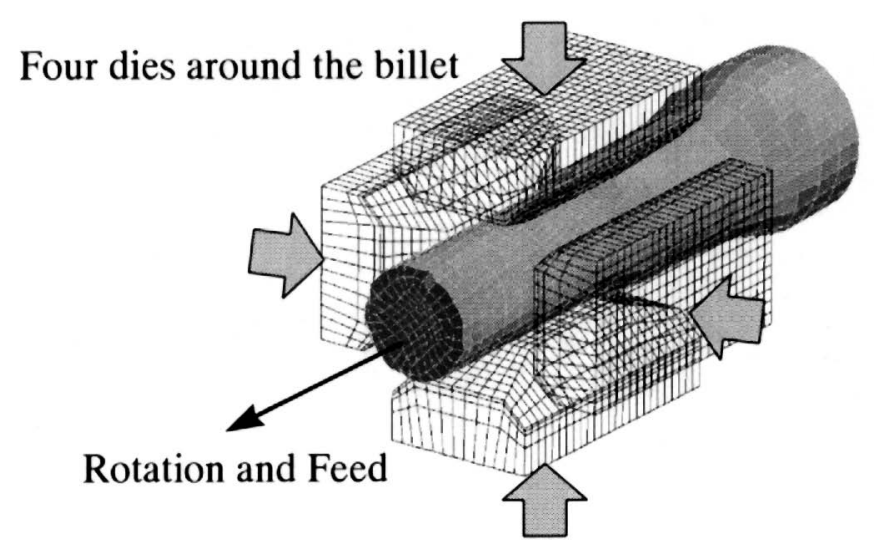

Figure 1 Schematic diagram of the radial forging machine

To analyze this process, 3-dimensional calculations must be done. 3-dimensional FEM software DEFORM-3D was used for this investigation. The analytical model and boundary conditions are shown in Figure 2. The billet model was 1/16 of an actual billet shape to save calculation time. Heat transfer conditions between the billet surface and the atmosphere and dies were added. Mirror symmetry conditions were also added in divided surfaces of the billet model. The billet was treated as a rigid plastic body with deformation resistance, specific heat, and thermal conductivity. The die model was treated as a rigid body with specific heat and thermal conductivity. Two dies were placed at a right angle to each other.

In the actual process, the billet is fed out with rotation, but in this analysis the dies were set to rotate around the billet as shown in Figure 3. Under these conditions, the process of transferring the billet from the heating furnace to the forging machine and the subsequent forging process was simulated.

These procedures of the numerical simulation were applied for the both calculations of $155 \mathrm{~mm}$ and $220 \mathrm{~mm}$ diameter billets.

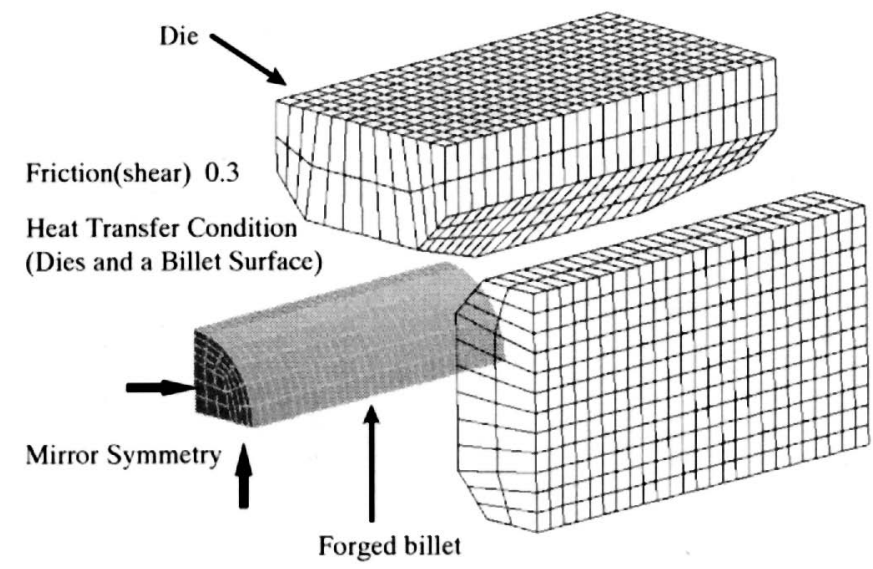

Figure 2 The analytical model and boundary conditions 

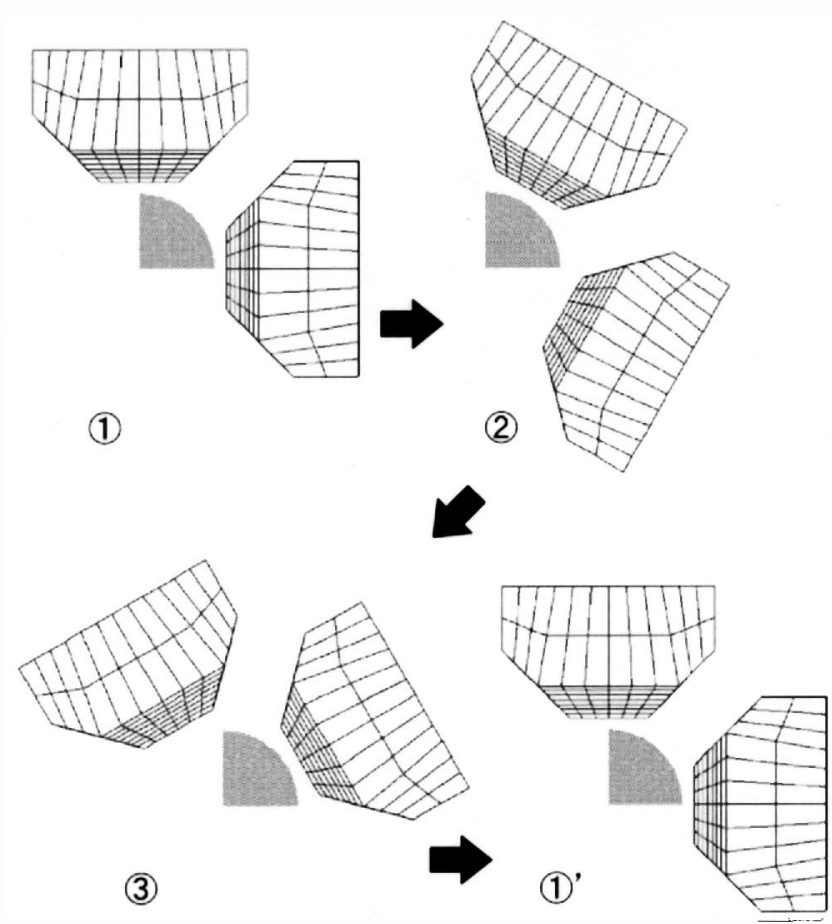

Figure 3 Motion of die at numerical simulation during forging

\section{Physical Simulation}

The predictions of microstructure were carried out by physical simulation; multi-stage plane strain compression tests by Gleeble3800 as shown in Figure 4. The test pieces for the physical simulations were taken from the same billets used for actual forging before it was forged by SMX. The chemical compositions and the grain sizes of the test pieces for the both physical simulations of $155 \mathrm{~mm}$ and $220 \mathrm{~mm}$ diameter billets are shown in Table 1 respectively. The size of the test piece was $10 \mathrm{~mm}$ in the $\mathrm{T}$ direction $\times 15 \mathrm{~mm}$ in the $\mathrm{L}$ direction $\times 20 \mathrm{~mm}$ in the $\mathrm{W}$ direction. In this simulation the temperature and strain at each stages was set according to the results obtained by the numerical simulation. Electrical resistance heating was used to control the temperature of the test piece, and the tests were carried out in Ar atmosphere.

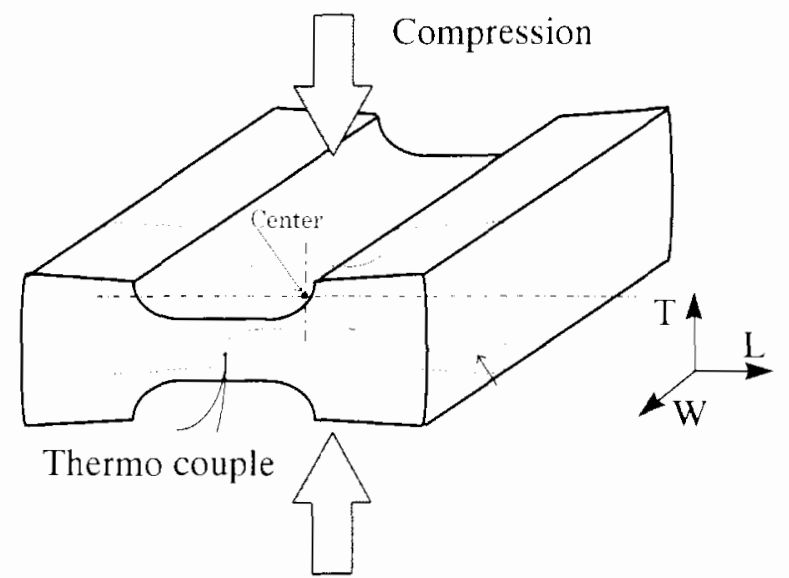

Figure 4 Schematic diagram of the plane strain compression test 
Table 1 Chemical compositions and grain sizes of the test pieces used for the physical simulations and for actual forging

\begin{tabular}{|c|c|c|c|c|c|c|c|c|c|c|c|}
\hline \multirow{2}{*}{$\begin{array}{c}\text { Billet size } \\
\text { before forging }\end{array}$} & \multicolumn{8}{|c|}{ Chemical composition (mass \%) } & \multicolumn{3}{|c|}{ ASTMG.S.No. } \\
\hline & $\mathrm{C}$ & $\mathrm{Ni}$ & $\mathrm{rr}$ & Mo & $\mathrm{Al}$ & $\mathrm{Ti}$ & $\mathrm{Nb}$ & & רו & $\mathrm{D} / 4$ & $\mathrm{D} / 8$ \\
\hline & & 53.1 & 18.0 & 3.0) & 0.44 & 1.14 & 5.41 & & & & 7 \\
\hline $\begin{array}{c}320 \mathrm{~mm} \\
\text { tagonal shap }\end{array}$ & & 2.5 & 18.6 & 3.1 & 0.00 & 1.00 & 5.11 & Bal. & $\begin{array}{c}860 \% \\
+1 \\
\end{array}$ & $\begin{array}{r}(20 \\
+1 \\
\end{array}$ & $\begin{array}{r}+1 \\
\end{array}$ \\
\hline
\end{tabular}

The strain distribution exists in the small test piece after the compression tests. The effective strain distribution was also calculated, then the center position of the test piece was adapted as an observed area of the microstructure, namely the amount of the compression at each stage was adjusted to give the same strain at the center position of the test piece as the effective strain obtained by the numerical simulations of the billets. Figure 5 shows the strain distribution and the observed area of the test piece.

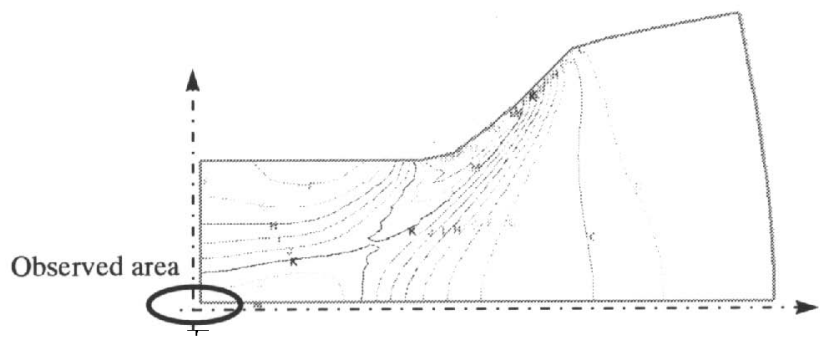

(a) The effective strain distribution of the test piece( $1 / 4$ model)

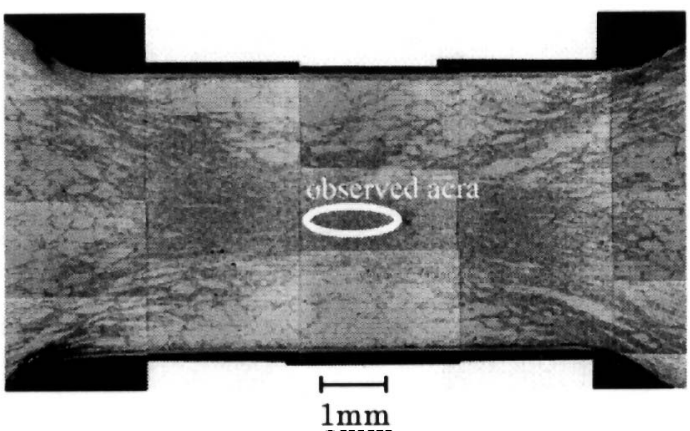

(b) Cross section of test piece

Figure 5 The observed area of the plane strain compression test piece

$155 \mathrm{~mm}$ Billet in Diameter

Results and Discussions

Numerical simulation In this simulation, $330 \mathrm{~mm}$ diameter billet was forged to $155 \mathrm{~mm}$ diameter billet by 9 passes. An example of the transitions of strains and temperatures by the numerical simulation was shown in Figure 6.

The time when the billet was extracted from the furnace was set to be 0 sec. Transitions of the strain and the temperature are shown at D/2(center), D/4(mid-radius), $\mathrm{D} / 8(1 / 8$ of diameter from the surface), and surface position of the billet, respectively, and the actual temperature change at the surface during forging was also shown in Figure 6. Since the position where the data were taken was near the edge in longitudinal direction of the billet 
model, momentary increase of the strain and the temperature by deformation was observed at the early stage of 1 -st pass and at the later stage of 2-nd pass.

The highest effective strain was obtained at the surface, and the lowest one was at the center. The amount of effective strain is $\mathrm{D} / 2<\mathrm{D} / 4<\mathrm{D} / 8<$ surface.

The calculated and measured temperatures at the surface were similar. The temperature at the surface was lower than that at inner position, because the cooling rate was faster at the surface than in the center, although the amount of temperature rise at the surface by deformation was larger than that in the center, because the increase of the strain at the surface is larger than that in the center. As before, the transitions of temperature and strain of all the internal regions can be calculated by this numerical simulation.

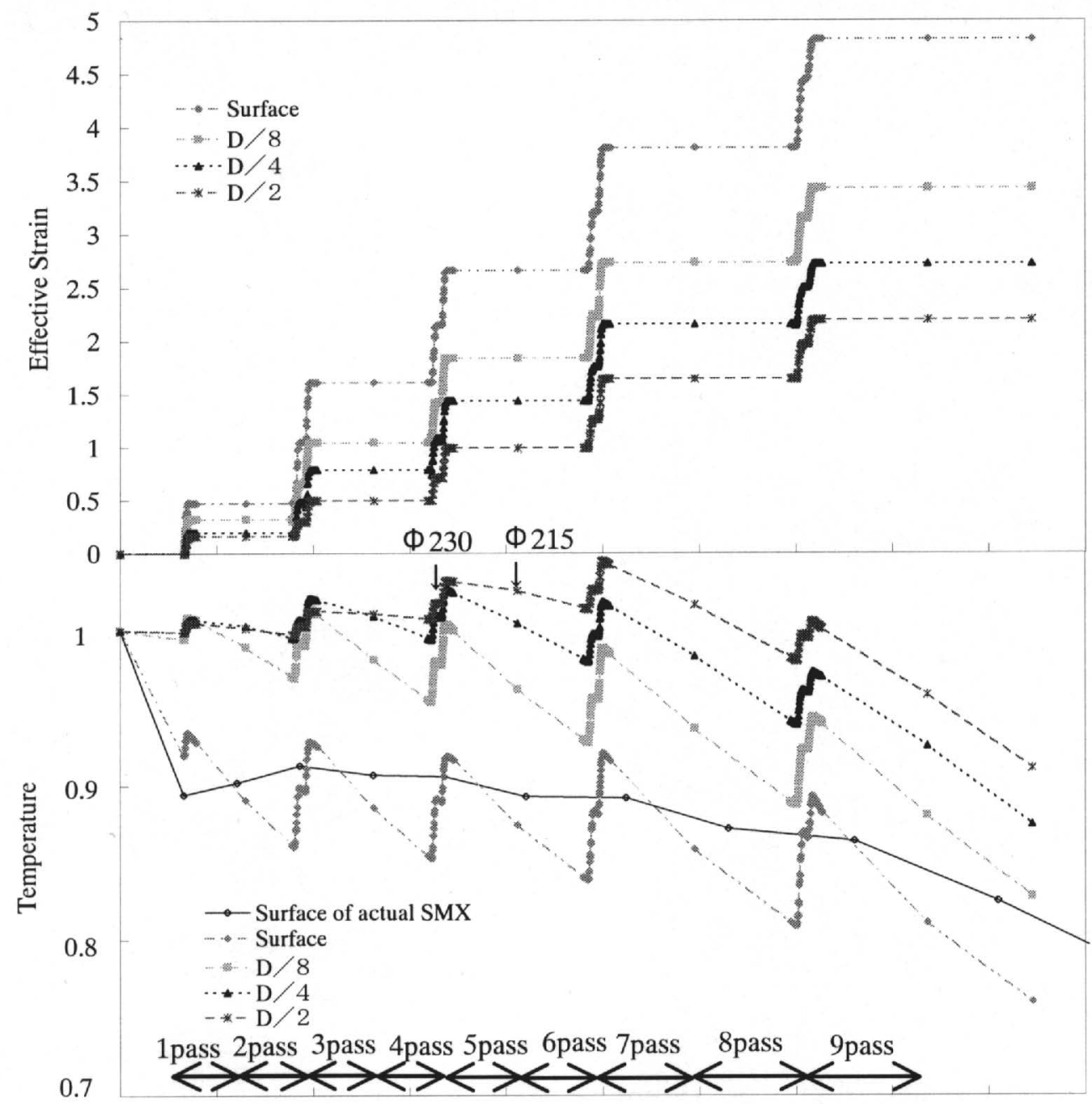

Time

Figure 6 The transition of strain and temperature of $155 \mathrm{~mm}$ billet during forging *D/2:Center, $\mathrm{D} / 4$ :Mid-radius, $\mathrm{D} / 8$ :One eighth of diameter from the surface

Microstructures obtained by physical simulation and actual forging The plain strain compression tests were carried out as the physical simulation. The test pieces were discontinuously compressed 9 times at the temperatures and the strains according to the numerical simulation. 
Microstructures obtained from physical simulation are shown in Figure 7. Fine grain sizes were obtained by this simulation. Grain size at $\mathrm{D} / 8$ position was finer than that at $\mathrm{D} / 2$ position, because of lower forging temperature.

Actual forging by hydraulic radial forging machine was carried out at the same conditions of the simulation. Microstructures by actual forging were also shown in Figure 7. The grain sizes at any position were similar to those obtained by the simulation.

Thus, it was confirmed that these simulations could predict the microstructures of actually forged products in all of the regions.

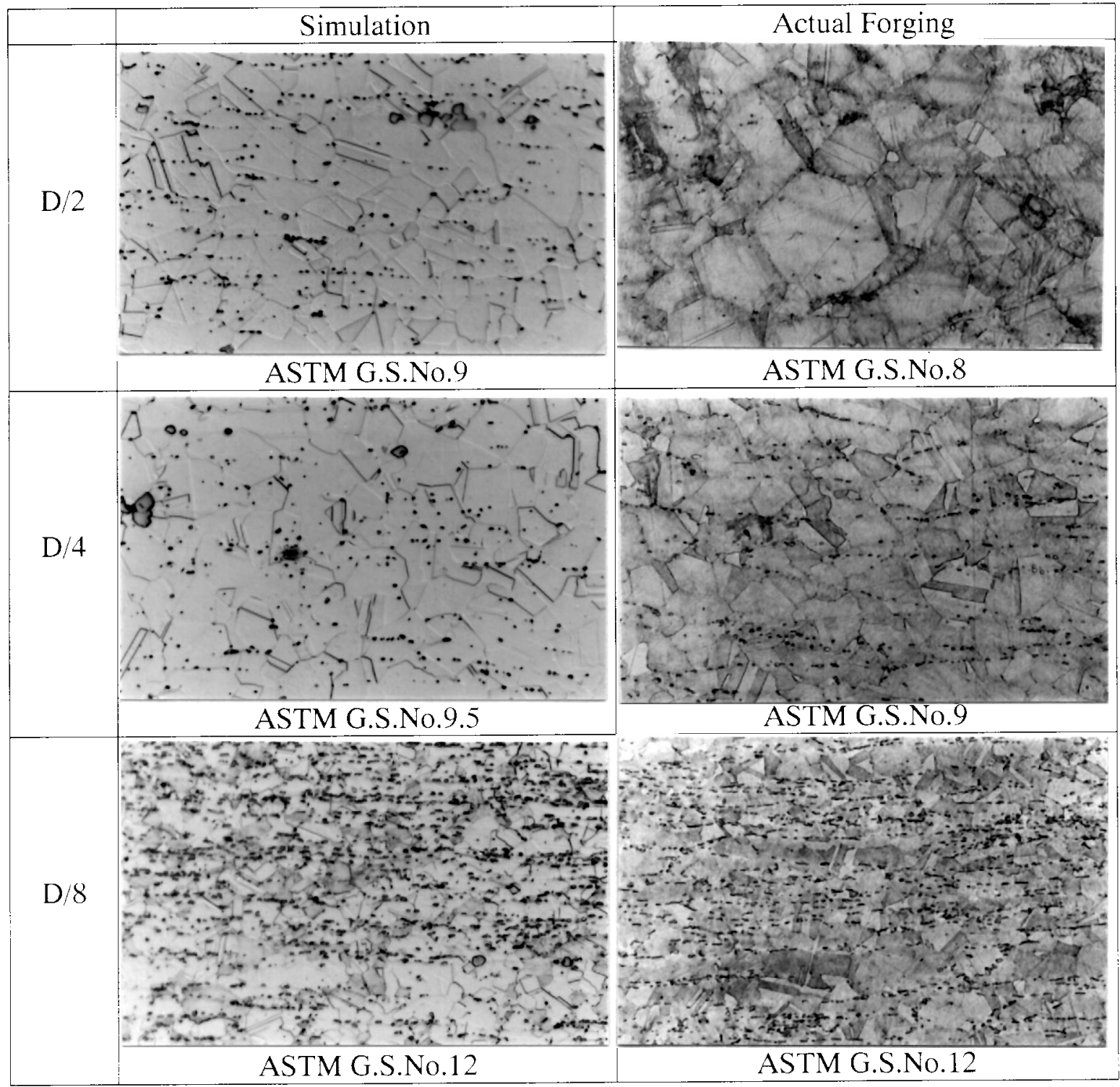

Figure 7 Microstructures of the physical simulation and the actual forging ( $155 \mathrm{~mm}$ billet)

$\mathrm{D} / 2$ :Center, D/4:Mid-radius, D/8: One eighth of diameter from the surface $25 \mu \mathrm{m}$

$220 \mathrm{~mm}$ Billet in Diameter

Numerical simulation In this simulation $320 \mathrm{~mm}$ octagonal shaped billet was forged to $220 \mathrm{~mm}$ diameter billet. The transitions of the strain and the temperature by the numerical simulation were shown in Figure 8. In this simulation, the forging speed (the cycle time of stroke) was 
intentionally lowered compared to that of $155 \mathrm{~mm}$ diameter billet to prevent from increase of the temperature by deformation especially at $\mathrm{D} / 2$ position.

The calculated effective strains were the highest at the surface and the lowest at $D / 2$, showing the same tendency as the result on $155 \mathrm{~mm}$ diameter billet.

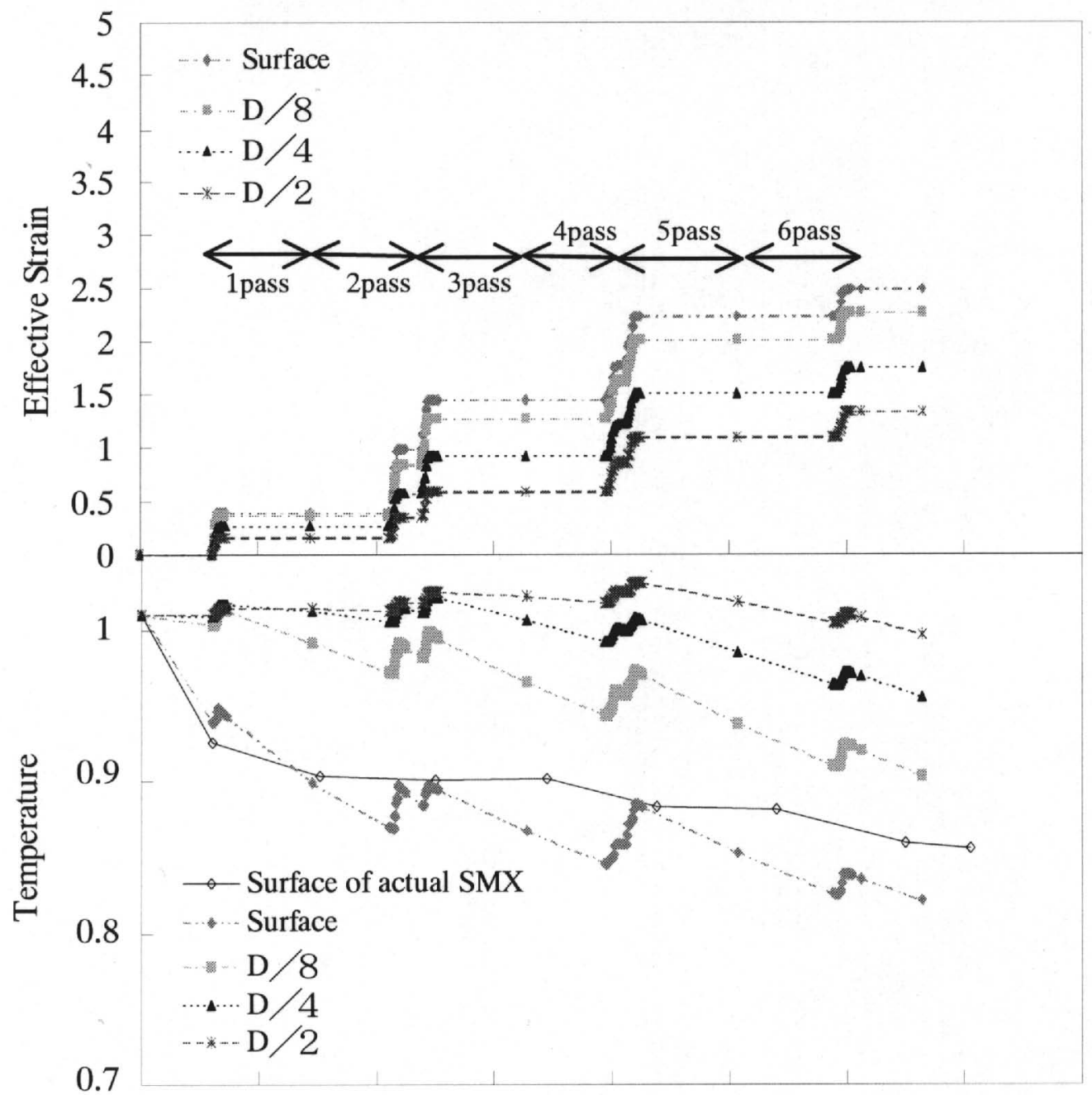

Time

Figure 8 The transition of strain and temperature of $220 \mathrm{~mm}$ billet during forging $* \mathrm{D} / 2$ :Center, $\mathrm{D} / 4$ :Mid-radius, $\mathrm{D} / 8$ :One eighth of diameter from the surface

Microstructures obtained from physical simulation and actual forging The plain strain compression tests were carried out as the physical simulation. The test pieces were discontinuously compressed 6 times at the temperatures and the strains according to the numerical simulation.

Figure 9 shows the results of the physical simulations and the actual forging. Both microstructures were very similar at all of the regions. Therefore, it was confirmed that these simulations could predict the microstructures of various section sizes of the billets. 
Further, fine grain size No.7.5-9 in all of the regions was obtained for large section size (220 $\mathrm{mm}$ in diameter) billet.

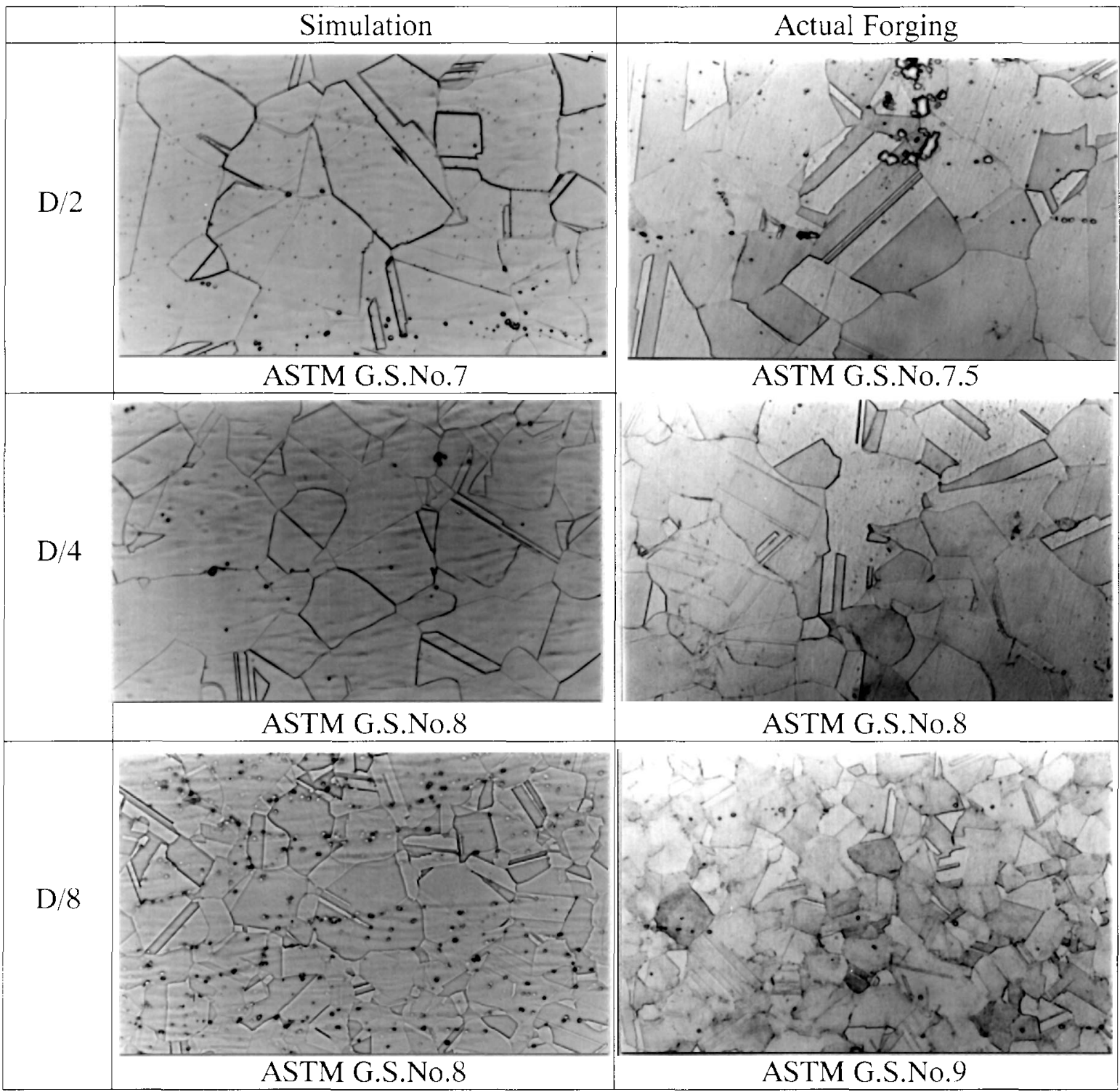

Figure 9 Microstructures of the physical simulations and the actual forging $(220 \mathrm{~mm}$ billet) $* \mathrm{D} / 2$ :Center,D/4: Mid-radius, D/8:One eighth of diameter from the surface $25 \% \mathrm{~m}$

\section{Comparison between $220 \mathrm{~mm}$ and $155 \mathrm{~mm}$ Billets}

Grains at $D / 2$ of the billets are generally coarse because of the higher temperature, especially such tendency is remarkable at $\mathrm{D} / 2$ of the large section size billet. In this study, grain size at D/2 of $155 \mathrm{~mm}$ billet is almost the same as that of the large section size of $220 \mathrm{~mm}$ billet, although the reduction area of $155 \mathrm{~mm}$ billet (4.5) was much larger than that of $220 \mathrm{~mm}$ billet (2.1). This was caused by the forging speed (the cycle time of stroke) of $220 \mathrm{~mm}$ billet which was intentionally lowered compared to that of $155 \mathrm{~mm}$ billet, so that the temperature of $\mathrm{D} / 2$ would not increase at the latter stage of forging. As a result, the fine grain size at D/2 of $220 \mathrm{~mm}$ billet was obtained and was equivalent to that of $155 \mathrm{~mm}$ billet. 


\section{Conclusions}

The grain size predictions of Alloy 718 billets by combining a numerical simulation and a physical simulation were carried out, then refining the grains in all the regions of large section size billet was tried by a hydraulic radial forging machine; SMX. The investigation draws the following conclusions.

1. The surface temperatures during forging calculated by numerical simulations of $155 \mathrm{~mm}$ and $220 \mathrm{~mm}$ diameter billets were similar to those by actual measurements respectively.

2. It was confirmed that the microstructures obtained by physical simulation of $155 \mathrm{~mm}$ and $220 \mathrm{~mm}$ diameter billets in all the regions were similar to those of the actually forged billets respectively, which indicates that the combination of the numerical simulation and the physical simulation is effective for estimating microstructures of complicated forged products.

3. The fine grain in all the regions of large section size billets both of 155mm(ASTMG.S.No.8-12) and 220mm (ASTMG.S.No.7.5-9) can be established.

\section{Reference}

1.L.A.Jackman et al., "Rotary Forge Processing of Direct Aged Inconel 718 for Air Craft Engine Shaft," Superalloys 718,625 and Various Derivatives, 1991, 125-132

2.C.A.Dandre et al., "Microstructural Evolution of Inconel 718 during Ingot Breakdown: Process Modeling and Validation," Material Science and Technology, 16(2000), 14-25

3.M.Caufman, and C.J.Scholl, "High Quality, High Strength Alloy 718 Billet Material Using Fine-Grain Conversion Practice," Superalloys 718, 625 and 706 Various Derivatives, 1989, $189-198$

4.D.Zhao et al., "Three Dimensional Computer Simulation of Alloy 718 Ingot Breakdown by Cogging," Superalloys 718,625 and Various Derivatives, $1997,163-172$

5.J.P.Domblesky et al., "Prediction of Grain Size during Multiple Pass Radial Forging of Alloy 718," Superalloys 718,625 and Various Derivatives, 1994, 263-273

6.T.Rodic, O.Wensel, A.Pristovsek, "3D Finite Element Analysis of Radial Forging using Process Frame Approach," Advanced Technology of Plasticity, 1(1999), 551-556

7.B.Antolovich, M.Evans, "Predicting Grain Size Evolution of UDIMET Alloy 718 during the Cogging Process through the Use of Numerical Analysis," Superalloys 2000. 39-47

8.Y.Isogawa et al., "Analysis of Temperature Transition and Deformation Behavior for Inconel718 by Rotary Forging," Proceedings of the Japan Science for Technology of Plasticity Spring Meeting. 1991, 541-544 